\title{
Rideshare mode potential in non-metropolitan areas of the northeastern United States
}

\author{
Brian H.Y. Lee \\ University of Vermont \\ bhylee@uvm.edu
}

\section{Matthew Coogan}

\section{New England Transportation Institute cooganmatt@aol.com}

\author{
Lisa Aultman-Hall \\ University of Vermont \\ laultman@uvm.edu
}

Thomas Adler

Resource System Group Inc. tom.adler@rsginc.com

\begin{abstract}
This study focuses on work commuters who currently rideshare, are potential rideshare commuters, or indicated a willingness to use rideshare services. Discrete choice models were developed with survey data of residents in the northeastern United States. Builtenvironment variables based on home and workplace locations were examined. While the socio-demographic characteristics of rideshare commuters and potential rideshare commuters were similar, characteristics of those indicating a willingness to use rideshare services were dissimilar, specifically women and younger individuals were uninterested in these programs. Those who live in denser areas were more likely to rideshare now, but less likely to indicate rideshare as their alternative to driving alone. Having a rural workplace corresponded to more ridesharing and being willing to use rideshare services, but less likely to indicate rideshare in place of driving alone. Many attitudinal variables were examined in the models; but interestingly most were not useful in explaining potential ridesharers or potential rideshare program participants. This analysis indicates that potential rideshare commuters may be demographically similar to existing rideshare commuters but live and work in more rural areas. Those who would participate in rideshare programs are a different set and should be further defined and targeted separately.
\end{abstract}

\section{Article history:}

Received: November 30, 2013

Received in revised form:

November 8, 2014

Accepted: December 23, 2014

Available online: July 1, 2015

\section{Introduction}

This study is focused on workers who indicated a potential to rideshare for their commute trip to work in a four-state region of the northeastern United States (Maine, New Hampshire, Vermont, and upper New York, excluding New York City). An online survey was conducted in 2012 with 1795 individuals who were employed full-time or part-time. A non-random sampling strategy was used to ensure that a sufficient number of both rural and urban residents were included in the sample.

Copyright 2015 Brian H.Y. Lee, Lisa Aultman-Hall, Matthew Coogan, \& Thomas Adler.

http://dx.doi.org/10.5198/jtlu.2015.669

ISSN: 1938-7849 | Licensed under the Creative Commons Attribution - Noncommercial License 3.0

The Journal of Transport and Land Use is the official journal of the World Society for Transport and Land Use (WSTLUR) and is published and sponsored by the University of Minnesota Center for Transportation Studies. This paper is also published with sponsorship from WSTLUR and the Institutes of Transportation Studies at the University of California, Davis, and the University of California, Berkeley. 
The online survey instrument was designed to investigate several topics related to work travel choices, behavior, and attitudes in northern non-metropolitan and rural areas. A better understanding of these factors was sought in order to inform the design of more sustainable transportation systems in the non-metropolitan context where longer distances create challenges for frequent biking and walking, and lower land-use density creates challenges for transit services. To that end, questions regarding ridesharing and shuttle-type services, as well as incentives for changes in vehicle purchase, home location, and alternative commuting options were included in the survey. Factors hypothesized to affect work travel were categorized into four groups: 1) household/demographic characteristics, 2) employment/commute attributes, 3) built-environment features, and 4) attitudes.

This paper presents three sets of discrete choice analysis: one to examine factors related to those who rideshare now, one to investigate factors related to those who we deem potential rideshare commuters, and one to investigate factors associated with willingness to participant in a rideshare program. Potential rideshare commuters were defined based on responses to questions about how drive-alone commuters would get to work if they could not drive alone. The rideshare program was defined as riding with someone registered with a rideshare program.

\section{$2 \quad$ Background}

Ridesharing, carpooling, "being dropped off," work shuttles, and vanpools take on numerous definitions in the literature and in everyday use. This challenge requires care when designing surveys such as that used here. Hunt and Macmillan (2007) broadly defined carpooling as any instance where more than one person was in a vehicle, whether or not there was any formal arrangement and the mode was used on a regular or occasional basis. In this study and analysis, we use a similar broad definition and consider the rideshare mode to be any use of an automobile that was not driven alone or a taxi. Survey questions used multiple terms when appropriate and provided examples when needed.

The National Report on Commuting Patterns and Trends indicates that work travel, while decreasing as a percent of total travel (18.1 percent nationwide in 2001), remains relatively constant as travel for other purposes has increased (Pisarski 2006). Travel to work will continue to be an important target for policy and planning whether related to congestion in urban areas or equity in rural areas. Over the last 50 years, there has been a steady loss of the ridesharing market share to driving alone (McGuckin and Srinivasan 2003). This paper is motivated by the proposition that regaining the rideshare mode is an important viable alternative to drive-alone work commuting in non-metropolitan areas.

Between 1950 and 2000, while rural population remained relatively constant in the United States, central city populations increased slightly and suburban population increased dramatically (Pisarski 2006). In metropolitan areas, there has been considerable focus on congestion as related to commuting travel and to a lesser extent mass transit as an alternative mode. Carpooling has been found to have a negative relationship with residential density and metropolitan size; this is attributed to dense and larger urban areas having better established public transit services (Silvia and Niemeier 2009; Hwang and Guiliano 1990; Charles and Kline 2004). In general, transit is included for commuting trips within metropolitan areas and between metropolitan areas, but commuting is more vehicle-oriented in suburban and rural areas (Pisarski 2006). Carpool users tend to travel farther than single-occupancy vehicle drivers (Teal 1987), and one study suggests that carpooling becomes appealing at a travel distance of 10 miles (Tsao and Lin 1999). Belz and Lee (2012) showed a slightly greater tendency toward interhousehold ridesharing than intra-household ridesharing as the distance to work increases.

In general, built environment variables such as those generated using home and work location in this study have been shown to impact mode choice. Residential density (households per area), employment density (employees per area), and mixed land use influence mode choice but also the probability 
of commuting by personal automobile (Kockelman 1997; Cervero 1996; Leck 2006; Frank and Pivo 1994). Employment density and workplace location (e.g., distance to a central business district) are also found to have correlations with work commute mode choice (Chatman 2003; Shiftan and Barlach 2012).

In terms of ride sharing specifically, some research suggests that socio-demographic characteristics only play a small role in the choice to carpool (Silvia and Niemeier 2009; Kaufman 2002; Hartgen 1977). Others (Belz and Lee 2012; Hartgen 1977) suggest that vehicle availability is an important determinant. Educational attainment has been suggested to play a larger role than other socio-demographic factors (Hartgen 1977). Belz and Lee (2012) find that individuals over the age of 40 years are less likely to rideshare compared to the younger population, with a preference for intra-household ridesharing over inter-household ridesharing. They also show ridesharing is more likely for females.

Perceptions of carpooling (e.g., constraints on independence, social requirements, and interpersonal rapport) may play a larger role than cost or convenience (Hwang and Guiliano 1990). Moreover, attitudes about the environment and pro-social concerns have strong influences on carpooling propensity (Van Lange et al. 1998). The survey used here includes a large number of attitudinal variables for modeling.

In summary, the relatively robust existing literature on ridesharing shows contradictory results for demographic, built environment, and attitudinal factors. This in itself motivated the design of the survey used here. There is limited work on potential rideshare commuters (as opposed to current rideshare commuters) and this focus is important.

\section{Data}

The project team identified four states of interest in the Northeast: Maine, New Hampshire, Vermont, and New York (focusing on "upstate"). Due to the differences in travel choices and behavior in and around major metropolitan areas, the Boston, Massachusetts, commuter shed in New Hampshire and the New York City commuter shed were excluded from the study area (14 counties total). The data were collected in two waves as outlined in Table 1.

Table 1: Survey sample details

\begin{tabular}{|l|l|l|}
\hline Wave & One & Two \\
\hline Sample frame & Address-based sample & Online research panel \\
\hline How respondents were contacted & First-class mail & Email from research panel \\
\hline Study area/respondents' home location & ME, NH, VT, and “upstate” NY & ME, NH, VT, and “upstate” NY \\
\hline Survey launch & July 12, 2012 & November 19, 2012 \\
\hline Survey close & August 16, 2012 & December 5, 2012 \\
\hline Total participants (1795) & 392 & 403 \\
\hline \multicolumn{1}{|c|}{ Maine } & 81 & 377 \\
\hline New Hampshire & 97 & 389 \\
\hline New York & 79 & 232 \\
\hline Vermont & 135 & 405 \\
\hline
\end{tabular}

A geographic stratification by state and county was used to ensure both a robust rural sample as well as a reasonable urban sample. Within the project study area, the sample was split evenly by state (25 percent of the total sample from each state). Within each state for Wave One, an address-based sample was identified using an even percentage by county, with Census-defined "urban" counties receiving twice as much sample as the non-urban counties. This ensured that a reasonably sized urban sample was 
obtained, along with the rural sample. This stratification, as opposed to a land area-based scheme, allows for future weighting using standard county-based Census data.

The total sample size of 20,000 invited respondents reflected the available budget. All invited participants received two first-class mailings in July 2012: a pre-notification (advanced notice) postcard and an invitation letter. The pre-notification postcard announced the study and conditioned the recipient to expect a survey invitation in the coming days. The invitation letter described the survey, asked for the recipient's participation, notified them of the survey incentive (one Apple iPad or one of three $\$ 100$ Amazon.com gift cards), and provided information to participate online. Residents invited to participate in Wave One were also given the option of calling a toll-free number to complete the survey over the phone with a trained operator.

Given the lower-than-expected response rate from Wave One (2 percent), the project team decided to administer the survey again in fall 2012 using a new recruitment method. Members of an online panel (maintained by ResearchNow) were invited to participate in the same survey. The approach was meant to supplement the survey effort from Wave One with the goal of achieving a combined sample size (Wave One plus Wave Two) of 500 per state (lower in Vermont based on available panel members). ResearchNow invited members of its online panel to participate. This effort was entirely electronic. Residents from the same set of states and counties were invited to participate in Wave Two; in other words, there was no difference between the study areas of Wave One and Wave Two. The sample sizes, however, were at the state level, meaning urban counties within the state were not double-sampled. That is to say, members of the online research panel were randomly selected to participate, regardless of their location within the study counties in each state.

Due to the focus on work travel, the respondents were filtered based on worker status. Homemakers, retired individuals, those not currently employed or a student employed less than 25 hours per week were terminated. These individuals were invited to ask another individual in the household to complete the survey and this resulted in 41 additional observations in Wave One and 18 additional observations in Wave Two. Self-employed individuals were included in the study.

At the conclusion of Wave Two, Wave One and Wave Two were merged. The online research panel data was checked for quality, which involved removing 118 respondents for either speeding through the survey or "straight-lining" (e.g., select "somewhat agree" for all attitude questions). A total of 41 individuals were removed from the sample for analysis because they indicated a home location outside the four-state study area. One additional respondent was removed for providing inconsistent answers. The final sample sizes are summarized in Table 1.

\section{$4 \quad$ Methodology}

The purpose of this research is twofold: characterize those who are rideshare commuters; and distinguish those who show interests in ridesharing for work purpose either as a potential ridesharer or by participating in a rideshare program. The following sections describe the methods used to examine these questions.

\subsection{Model 1: Who is ridesharing?}

To gain a better understanding of current rideshare commuters, responses from the following survey question were used: "How did you get from home to your work location on your most recent workday?" Respondents were provided with a list of choices for their answer (drove alone, dropped off, carpool/ rode with others, vanpool, bus/public transit, taxi, bike, walk, other-please specify) and asked to select all that apply to allow for multi-modal home-to-work journeys and variations from day-to-day. Of the 
1795 respondents included in this analysis, only 40 people selected multiple modes. Those who selected "dropped off," "carpool/rode with others," and "vanpool" were recoded as "rideshare" ( $\mathrm{n}=137,7.63$ percent) and those who only chose other modes were considered "non-rideshare" ( $\mathrm{n}=1658,92.4$ percent). The mode distribution of the survey respondents, after recoding, is shown in Table 2 (note that "telecommuted" was derived from those who selected "other" and specified working from home).

Table 2: Distribution of travel modes for respondents' most recent home-to-work journey

\begin{tabular}{|l|c|c|c|c|c|c|c|c|}
\hline & \multirow{2}{*}{$\begin{array}{c}\text { Ride- } \\
\text { share* }\end{array}$} & \multicolumn{4}{|c|}{ Non-rideshare } & Total & \multirow{2}{*}{ N } \\
\cline { 3 - 7 } & Drove alone* & Bus* & Walk/ bike* & Tele-com-mute* & Other & modes & \\
\hline All (include multiple modes) & 137 & 1506 & 29 & 96 & 62 & 11 & 1841 & 1795 \\
\hline Those who used only one mode & 121 & 1474 & 22 & 71 & 61 & 6 & 1755 & 1755 \\
\hline Those who used multiple modes & 16 & 32 & 7 & 25 & 1 & 5 & 86 & 40 \\
\hline
\end{tabular}

* Includes respondents recoded from "other"

** Only includes respondents recoded from "other"

A binomial logistic regression model was developed with the "Rideshare" mode dummy as the dependent variable. A list of diverse explanatory variables, selected based on theory and the literature, were examined in this model to help explain who these rideshare commuters are. They include factors concerning household/demographic characteristics, employment/commute attributes, built-environment features, and attitudes (see Table 3). Most of these variables were derived from the survey data, while some built-environment variables were calculated in Geographic Information Systems (GIS) software using the geocoded home and work locations provided by the respondents.

Cross-tabulations between the rideshare indicator and the explanatory variables were conducted to help reveal relationships. Some variables were transformed, mostly from categorical or continuous forms to dummy variables, based on this intermediate step. Correlations between the explanatory variables were also examined to avoid over-specifying the model and help select appropriate ones for inclusion. 
Table 3: Explanatory variables examined

\begin{tabular}{|c|c|c|}
\hline & Variable & Measure \\
\hline \multirow{9}{*}{ 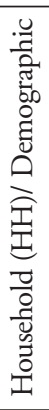 } & Age (yrs) & $<18,18-24,25-34,45-54,55-64,75-84,>85$ \\
\hline & Female (dummy) & 0,1 \\
\hline & Education & $\begin{array}{l}<\text { High school (HS), HS diploma, some college, associate degree, bachelor's degree, } \\
\text { graduate degree }\end{array}$ \\
\hline & Annual HH income $(\$ 1,000)$ & $<25,25-49,50-74,75-99,100-149,150-199,200-249,>250$ \\
\hline & Duration in current home (yrs) & $<1,1-5,6-10,>10$ \\
\hline & Household size & $1,2,3,4,5,6,>7$ \\
\hline & No. of licensed drivers & $0,1,2,3,>4$ \\
\hline & No. of vehicles available & $0,1,2,3,4,>5$ \\
\hline & Likeliness to move in next 5 yrs & Extremely unlikely, somewhat unlikely, neutral, somewhat likely, extremely likely \\
\hline \multirow{8}{*}{ 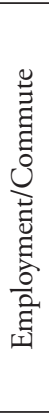 } & Employment status & Full-time, part-time, self-employed (FT or PT), student and employed \\
\hline & Occupation & $\begin{array}{l}\text { Agriculture, farming, forestry, mining; professional services/managerial; manufac- } \\
\text { turing/transportation; construction, carpentry; professional assistant/administra- } \\
\text { tive; sales, retail; education; other industry }\end{array}$ \\
\hline & Days/week worked outside home & $<3,3,4,5,>5$ \\
\hline & Work requires midday veh. trips & Yes, No \\
\hline & Telecommute frequency & Never, $<1 /$ mo., 1-3/mo., 1 day/wk, 2 days/wk, 3 days/wk, $>3$ days/wk \\
\hline & Work schedule flexibility & None, some, complete \\
\hline & Work arrival time & Continuous in minutes \\
\hline & Work commute travel time & Continuous in minutes \\
\hline \multirow{8}{*}{ 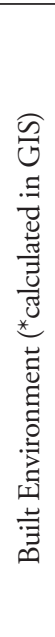 } & Neighborhood type & $\begin{array}{l}\text { City, downtown with a mix of offices, apartments, and shops; city, residential } \\
\text { neighborhood; suburban neighborhood, with a mix of houses, shops, and busi- } \\
\text { nesses; suburban neighborhood, with houses only; small town or rural village; } \\
\text { rural area, outside of a town or village }\end{array}$ \\
\hline & Neighborhood public transit & $\begin{array}{l}\text { Large bus; small bus; bus for special purposes, like medical or senior citizen } \\
\text { service; taxi; other; none; I do not know }\end{array}$ \\
\hline & \begin{tabular}{|l} 
Residential density* \\
\end{tabular} & Continuous in $\mathrm{HH} / \mathrm{km}^{2}$, for home and work locations \\
\hline & Retail location counts* & Continuous, within 1-km and 10-km radii and network, for home and work loc. \\
\hline & Distance to nearest retail* & Continuous in $\mathrm{km}$, for home and work locations \\
\hline & $\begin{array}{l}\text { Level of ruralness: Rural-urban commuting } \\
\text { area codes ver. } 2 \text { (RUCA2)* }\end{array}$ & $\begin{array}{l}\text { Census tract-based classification scheme that uses urbanized area and urban cluster } \\
\text { definitions with work commuting information to characterize all Census tracts } \\
\text { regarding their rural and urban status (http://depts.washington.edu/uwruca/), } \\
\text { codes } 1 \text { through } 10 \text { in increasing ruralness, for home and work locations } \\
\end{array}$ \\
\hline & \begin{tabular}{|l} 
Intersection counts* \\
\end{tabular} & Continuous, within 1-km and 10-km radii, for home and work locations \\
\hline & Length of road* & Continuous in $\mathrm{km}$, within 1-km and 10-km radii, for home and work locations \\
\hline \multirow[b]{2}{*}{ 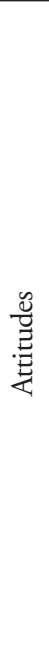 } & $\begin{array}{l}\text { Statements about next place one would want } \\
\text { to live } \\
\text { (Not important at all; not very important; } \\
\text { neutral; somewhat important; extremely } \\
\text { important) }\end{array}$ & $\begin{array}{l}\text { A home location that is close to work, school, and friends } \\
\text { A home with a large lot } \\
\text { A garage for two or more vehicles } \\
\text { Services that are nearby } \\
\text { A neighborhood where you could walk to a village or commercial center } \\
\text { A private home location with adequate separation from others }\end{array}$ \\
\hline & $\begin{array}{l}\text { Statements about a hypothetical work com- } \\
\text { mute shuttle service } \\
\text { (Strongly disagree; somewhat disagree; neu- } \\
\text { tral; somewhat agree; strongly agree) }\end{array}$ & $\begin{array}{l}\text { I am concerned about traveling with people that I do not know } \\
\text { It would be easier for me to take the shuttle service if I were not so concerned } \\
\text { about getting to and from work in the shortest amount of time } \\
\text { It would be easier for me to take the shuttle service if I were not so concerned } \\
\text { about my need to come and go when I want to } \\
\text { I prefer to be the driver, not a passenger } \\
\text { I use the most convenient form of transportation regardless of cost } \\
\text { How I get to work is really up to me, and I could do this if I chose to } \\
\text { It is important to me to control the radio and the a/c in the vehicle }\end{array}$ \\
\hline
\end{tabular}




\subsection{Model 2: Who are potential rideshare commuters?}

In theory, rideshare can be a realistic alternative to driving alone for most commuters; drivers with vehicles usually have unused capacity to provide a ride for others, and those who do not drive can be matched with those who do. There are, however, various obstacles that would prevent commuters from considering rideshare as their work trip travel mode and the reasons can be geographical, logistical, and attitudinal in nature. To examine who considered that they could become a rideshare commuter, discrete choice models were developed for two survey questions using the same explanatory variables (Table 3). Depending on any relationships revealed in additional cross-tabulations that were performed, some variables were transformed in different ways than what was done in the previous analysis.

One survey question was asked of those who selected "drove alone" in the home-to-work journey question analyzed above ( $\mathrm{n}=1503)$ : "If you could not drive alone to work, how would you most likely get there?" The mode choices were the same as the ones for that previous question, except without the "drove alone" option, and "I don't know" was added. Again, respondents were permitted to select multiple responses. The distribution of the alternative travel modes to driving alone is shown in Table 4.

Table 4: Distribution of alternative travel mode for respondents' who "drove alone"

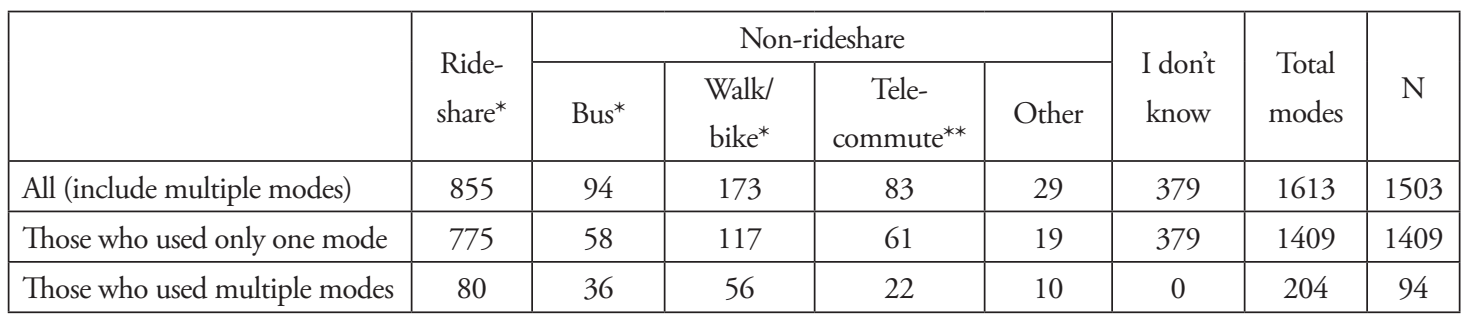

* Includes respondents recoded from "other"

** Only includes respondents recoded from "other"

A majority of this sample subset selected "dropped off," "carpool/rode with others," and "vanpool," which were aggregated and recoded as "rideshare" ( $\mathrm{n}=855,56.9$ percent). Note that fully one-quarter of these solo drivers did not know of another travel option ( $n=379,25.2$ percent). Since rideshare and "I don't know" choices were the first and second most popular, they are included as separate alternatives in the discrete choice analysis. Although respondents who selected "I don't know" did not state a mode choice per se, this group is modeled as an alternative because it is sufficiently large and can provide insights into understanding those who do not think they have alternatives to driving alone to work. The remaining non-rideshare options were initially modeled as a single choice for those who did not select one of the "rideshare" modes or "I don't know." After developing some trial models and experimenting with other choice sets, it was determined that those who selected "telecommute" were distinct enough to warrant being a separate choice. Thus, the modeled choice set in this analysis included four stated alternatives: "rideshare," "non-rideshare," "telecommute" (i.e., would not make a work trip), and "I don't know." These four choices were first modeled in a multinomial logit (MNL) model using a maximum likelihood estimation approach, with "rideshare" as the reference. Then, various nesting structures were examined in nested logit (NL) models to test whether some choices were well-suited to be grouped into a nest together; these trials included:

- Know (rideshare, non-rideshare, telecommute) vs. I don't know;

- Make trip (rideshare, non-rideshare) vs. do not make trip (telecommute, I don't know);

- Make trip (rideshare, non-rideshare) vs. telecommute vs. I don't know. 
In the end, the best model was selected from this set of MNL and NL models based on model fit, theory, and interpretation.

\subsection{Model 3: Who will participate in a rideshare program?}

The other survey question to be analyzed was asked of the entire survey sample, "Should the situation arise, would you be willing to ride with someone you did not know personally but who was registered with a rideshare program?" Most respondents answered "yes" ( $\mathrm{n}=1087,60.6$ percent); 708 (39.4 percent) answered "no." Surprisingly, the distributions of travel modes for respondents' most recent hometo-work journey are almost identical between those who said "yes" to a rideshare program compared to those who said "no." Since this is a dichotomous variable, a binomial logistic regression model was developed to help understand those who say they would use a rideshare program.

\section{$5 \quad$ Results}

\subsection{Model 1: Who is ridesharing?}

The results for Model 1-corresponding to the question of "Who is ridesharing?" —are shown in Table 5. It includes explanatory variables from all four categories (household/demographic, employment/ commute, built environment, and attitudes) and has a Nagelkerke pseudo r-square of 0.166 . All variables included in this model are statistically significant, to at least 95 percent confidence, and they all have the expected signs.

Numerous variable interactions were examined but only one pair, the female and younger than 55 dummy variables, was statistically significant. To interpret this interaction, it is necessary to include the coefficient for the interaction as well as those for the individual dummy variables. The model results suggest that females who are younger than $55(-0.9374+0.7469+0.7347=0.5442)$ are more likely to rideshare, if all else is equal, than older males (i.e., the reference group), but less likely to rideshare than younger males $(0.7347)$ and older females (0.7469). This finding is consistent with previous research that found females and younger commuters to be more likely to rideshare (Belz and Lee 2012).

Other household/demographic variables found to be significant in Model 1 include dummy variables for not having attained any type of educational degree, being in a multi-person household, and having more licensed drivers in the household than there are vehicles. All of these variables were found to positively explain rideshare behavior. In particular, having fewer vehicles than drivers appears to be the largest influence on those who used rideshare in their most recent home-to-work journey, which is consistent with the literature (Belz and Lee 2012, Hartgen 1977). Household income was not found to be related to rideshare, but it is highly correlated with educational level and age. 
Table 5: Model 1-Binomial logistic regression model of the "rideshare" mode dummy for respondents' most recent home-to-work journey

\begin{tabular}{|c|c|c|c|}
\hline Variable & Coefficient & Wald Z & $\operatorname{Pr}(>|\mathrm{Z}|)$ \\
\hline Intercept & -5.643 & -7.85 & $<0.0001$ \\
\hline \multicolumn{4}{|l|}{ Household/demographic } \\
\hline Female & 0.747 & 2.11 & 0.0349 \\
\hline Younger than 55 & 0.735 & 2.14 & 0.0327 \\
\hline No educational degree & 0.475 & 2.34 & 0.0191 \\
\hline Multi-person household & 1.055 & 2.76 & 0.0058 \\
\hline More drivers than vehicles in household & 1.223 & 5.62 & $<0.0001$ \\
\hline Female $\times$ younger than 55 & -0.937 & 2.22 & 0.0265 \\
\hline \multicolumn{4}{|l|}{ Employment/commute } \\
\hline Work less than 4 days/week & -0.668 & -2.35 & 0.0186 \\
\hline Work requires midday vehicle trips & -0.621 & -2.36 & 0.0185 \\
\hline Reported travel time to work (minutes) & 0.023 & 3.89 & $<0.0001$ \\
\hline \multicolumn{4}{|l|}{ Built environment } \\
\hline Home in dense tract $\left(\geq 420 \mathrm{HH} / \mathrm{km}^{2}\right)$ & 0.530 & 2.15 & 0.0318 \\
\hline Home near CBD $(\leq 21 / 4 \mathrm{~km})$ & 1.123 & 2.35 & 0.0188 \\
\hline Work area ruralness (RUCA2; 1 through 10) & 0.117 & 3.77 & 0.0002 \\
\hline \multicolumn{4}{|l|}{ Attitudes } \\
\hline Prefer to be driver over passenger & -0.466 & -2.33 & 0.0197 \\
\hline Not important to live close to work, school, friends & -0.899 & -2.17 & 0.0298 \\
\hline Important to have private home location & -0.437 & -2.16 & 0.0306 \\
\hline Number of observations & 1,795 & & \\
\hline Rideshare & 137 & & \\
\hline Non-rideshare & 1,658 & & \\
\hline Nagelkerke $\mathrm{R}^{2}$ & 0.166 & & \\
\hline
\end{tabular}

There were several employment/commute variables of note. Those who work less than four days a week or whose work requires midday vehicle trips are less likely to rideshare to work. The reported travel times, however, are positively correlated with rideshare behavior. This last variable could simply mean that ridesharing generally takes more time than non-rideshare mode trips, but it could also confirm that longer trips increase the propensity of commuters to rideshare, which has been found in previous work (Tsao and Lin 1999; Teal 1987; Belz and Lee 2012).

Three built-environment variables, two based on the home location and one based on the work location, were statistically significant in Model 1 . Those who live in Census tracts with high residential densities (defined as $\geq 420$ households/kilometer ${ }^{2}$ ) or whose homes are near a central business district (CBD; defined as $\leq 2.25$ kilometers) have greater propensity to rideshare. Note that the thresholds for these dummy variables were determined empirically by analyzing the distributions and trying different values in the model; the non-linear, irregular nature of the distributions did not lend the continuous variables themselves to be good candidates for inclusion into the model. The rural-urban commuting area codes version 2 (RUCA2) metric, a Census tract-based classification scheme from 1 through 10 that uses urbanized area and urban cluster definitions with work commuting information to characterize all Census tracts regarding their rural and urban status, suggest that the more urban the work location 
is, the most likely commuters are to rideshare. This is comparable to results in previous work where employment density around the workplace was found to be positively correlated with mode choice (Kockelman 1997, Cervero 1996, Leck 2006, Frank and Pivo 1994) and ridesharing behavior specifically (Belz and Lee 2012).

Finally, three attitudinal variables were found to be negatively correlated with rideshare. They suggest that commuters who prefer to drive instead of being a passenger; those who do not find it important to live close to work, school, and friends; and those who value having a private home location are all less likely to engage in rideshares. These characteristics all fit well with known attitudes concerning mode choice (Van Lange et al. 1998).

\subsection{Model 2: Who are potential rideshare commuters?}

Table 6 below shows the results for Model 2 and it includes a best-fit MNL model (McFadden r-square of 0.1384 ) and three NL models with different nesting structures, all with the "rideshare" alternative as the reference choice. The alternative specific constants for the MNL model reveal that all else being equal, people favor a non-rideshare mode as an alternative to driving alone than ridesharing, but they are more likely to rideshare than not knowing any other choices (i.e., "I don't know") or telecommuting.

Of the three nesting structures examined, two (NL1 and NL3), resulted in the estimated log-sum coefficient $(\lambda)$ being greater than one or less than zero, which implies that there is more substitution across the nests than within (for $\lambda>1$ ) or that the nests are inconsistent with utility maximizing behavior $($ for $\lambda<0$ ). Further, many coefficients in these two models have signs that are opposite to what is expected and their magnitudes also changed dramatically from the MNL model. For NL2, the remaining model where $0>\lambda>1$, a likelihood ratio test comparing it with the MNL model was not able to reject the hypothesis that the MNL model is the true model. These results, therefore, suggest that none of the nesting structures tested is appropriate. The rest of the discussion in this section will focus on the MNL model.

Since none of the explanatory variables were alternative specific, each was entered into the model as three separate interactions with the three non-reference alternatives. Table 6 shows that each explanatory variable in the MNL model has at least one statistically significant interaction with the alternatives. Similar to Model 1, the household/demographic dummy variables for female, younger than 55 years, not having attained any type of educational degree, and being in a multi-person household were all correlated with one or more alternatives and had the expected sign. Females, younger commuters, and those who live with others are more likely to choose rideshare than a non-rideshare mode. Further, younger communal dwellers are also more likely to participate in ridesharing than not knowing what to do if they cannot drive alone. This may point to the resourcefulness of younger workers and the propensity for people to engage in intra-household rideshares (9). Having a lower educational level is associated with a higher likelihood of not knowing or having an alternative travel mode. 
Table 6: Models 2-Multinomial logit and nest logit models of alternative travel mode for respondents' who "drove alone"

\begin{tabular}{|c|c|c|c|c|c|c|c|c|}
\hline & \multicolumn{2}{|c|}{ MNL } & \multicolumn{2}{|c|}{ NL1 } & \multicolumn{2}{|c|}{ NL2 } & \multicolumn{2}{|c|}{ NL3 } \\
\hline Nest 1 & \multicolumn{2}{|c|}{$\mathrm{n} / \mathrm{a}$} & \multicolumn{2}{|c|}{ RS, NRS, TEL } & \multicolumn{2}{|c|}{ RS, NRS } & \multicolumn{2}{|c|}{ RS, NRS } \\
\hline Nest 2 & \multicolumn{2}{|c|}{$\mathrm{n} / \mathrm{a}$} & \multicolumn{2}{|c|}{ IDK } & \multicolumn{2}{|c|}{ TEL, IDK } & \multicolumn{2}{|c|}{ TEL } \\
\hline Nest 3 & \multicolumn{2}{|c|}{$\mathrm{n} / \mathrm{a}$} & \multicolumn{2}{|c|}{$\mathrm{n} / \mathrm{a}$} & \multicolumn{2}{|c|}{$\mathrm{n} / \mathrm{a}$} & \multicolumn{2}{|c|}{ IDK } \\
\hline Variables & Coeff. & t-val. & Coeff. & t-val. & Coeff. & t-val. & Coeff. & t-val. \\
\hline \multicolumn{9}{|l|}{ "I don't know" choice $\times$} \\
\hline Intercept & -0.911 & -3.51 & -0.395 & -1.03 & -1.754 & -5.10 & -1.402 & -4.18 \\
\hline Female & -0.019 & -0.14 & -0.095 & -0.61 & -0.171 & -1.06 & 0.037 & 0.27 \\
\hline Younger than 55 & -0.638 & -4.74 & -0.690 & -4.60 & -0.291 & -1.87 & -0.584 & -4.33 \\
\hline No educational degree & 0.289 & 1.94 & 0.236 & 1.43 & 0.146 & 0.85 & 0.308 & 2.09 \\
\hline Multi-person household & -0.863 & -4.88 & -1.131 & -4.89 & -0.605 & -2.78 & -0.660 & -3.56 \\
\hline Work less than 4 days/week & 0.222 & 1.32 & 0.425 & 2.08 & 0.913 & 4.19 & 0.186 & 1.15 \\
\hline Work requires midday vehicle trips & 0.517 & 3.50 & 0.495 & 3.01 & 0.233 & 1.36 & 0.512 & 3.53 \\
\hline Reported travel time to work (minutes) & 0.036 & 8.16 & 0.033 & 6.29 & 0.055 & 8.84 & 0.042 & 7.58 \\
\hline Have work schedule flexibility & -0.177 & -1.29 & 0.017 & 0.09 & 0.427 & 1.88 & -0.247 & -1.80 \\
\hline No transit available in neighborhood & 0.317 & 2.26 & 0.213 & 1.32 & 0.254 & 1.54 & 0.387 & 2.72 \\
\hline Home in dense tract $\left(\geq 420 \mathrm{HH} / \mathrm{km}^{2}\right)$ & 0.124 & 0.61 & 0.251 & 1.03 & 0.283 & 1.20 & 0.022 & 0.10 \\
\hline No. of retailers within $1 \mathrm{~km}$ of work & 0.000 & 0.30 & 0.001 & 0.73 & 0.001 & 0.68 & 0.000 & -0.17 \\
\hline \multicolumn{9}{|l|}{ "Non-rideshare" choice $\times$} \\
\hline Intercept & 0.635 & 1.97 & 1.231 & 1.75 & 0.068 & 0.31 & 0.098 & 0.40 \\
\hline Female & -0.411 & -2.41 & -0.810 & -1.91 & -0.051 & -0.31 & -0.073 & -0.41 \\
\hline Younger than 55 & -0.399 & -2.31 & -0.814 & -1.99 & -0.045 & -0.31 & -0.064 & -0.40 \\
\hline No educational degree & -0.202 & -1.00 & -0.359 & -0.83 & -0.029 & -0.31 & -0.041 & -0.39 \\
\hline Multi-person household & -1.080 & -5.41 & -2.331 & -3.18 & -0.118 & -0.32 & -0.170 & -0.41 \\
\hline Work less than 4 days/week & 0.217 & 1.02 & 0.533 & 1.12 & 0.026 & 0.30 & 0.036 & 0.39 \\
\hline Work requires midday vehicle trips & -0.071 & -0.35 & -0.267 & -0.62 & -0.004 & -0.15 & -0.007 & -0.17 \\
\hline Reported travel time to work (minutes) & -0.069 & -7.03 & -0.144 & -3.34 & -0.008 & -0.31 & -0.012 & -0.41 \\
\hline Have work schedule flexibility & 0.623 & 3.28 & 1.377 & 2.48 & 0.067 & 0.31 & 0.096 & 0.41 \\
\hline No transit available in neighborhood & -0.665 & -3.35 & -1.468 & -2.57 & -0.071 & -0.31 & -0.102 & -0.40 \\
\hline Home in dense tract $\left(\geq 420 \mathrm{HH} / \mathrm{km}^{2}\right)$ & 0.422 & 2.08 & 0.785 & 1.66 & 0.051 & 0.31 & 0.072 & 0.40 \\
\hline No. of retailers within $1 \mathrm{~km}$ of work & 0.002 & 2.27 & 0.005 & 1.77 & 0.000 & 0.32 & 0.001 & 0.42 \\
\hline \multicolumn{9}{|l|}{ "Telecommute" choice $x$} \\
\hline Intercept & -5.620 & -7.56 & -11.6 & -3.30 & 8.805 & 2.25 & -6.153 & -7.46 \\
\hline Female & -0.356 & -1.26 & -0.621 & -1.02 & 1.004 & 1.68 & -0.295 & -1.02 \\
\hline Younger than 55 & 0.113 & 0.39 & 0.294 & 0.48 & -1.876 & -2.86 & 0.167 & 0.53 \\
\hline No educational degree & -0.610 & -1.45 & -1.352 & -1.22 & 0.594 & 0.87 & -0.597 & -1.19 \\
\hline Multi-person household & 0.163 & 0.35 & -0.059 & -0.06 & -0.238 & -0.35 & 0.388 & 0.79 \\
\hline Work less than 4 days/week & 1.366 & 4.72 & 2.819 & 2.88 & -2.157 & -2.44 & 1.319 & 3.94 \\
\hline Work requires midday vehicle trips & 0.455 & 1.55 & 0.247 & 0.38 & 2.473 & 3.14 & 0.450 & 1.36 \\
\hline Reported travel time to work (minutes) & 0.044 & 5.37 & 0.092 & 3.45 & -0.011 & -0.51 & 0.050 & 5.52 \\
\hline Have work schedule flexibility & 1.653 & 3.57 & 3.642 & 2.37 & -4.972 & -2.53 & 1.627 & 2.86 \\
\hline No transit available in neighborhood & -0.010 & -0.03 & -0.086 & -0.14 & 0.979 & 1.67 & 0.050 & 0.16 \\
\hline Home in dense tract $\left(\geq 420 \mathrm{HH} / \mathrm{km}^{2}\right)$ & 0.370 & 0.93 & 0.865 & 1.06 & -1.212 & -1.66 & 0.271 & 0.71 \\
\hline No. of retailers within $1 \mathrm{~km}$ of work & 0.002 & 1.95 & 0.004 & 1.53 & 0.000 & -0.22 & 0.001 & 0.82 \\
\hline Nest 1 parameter $\left(\lambda_{1}\right)$ & $\mathrm{n} / \mathrm{a}$ & $\mathrm{n} / \mathrm{a}$ & 2.16 & 3.48 & 0.114 & 0.315 & 0.164 & 0.410 \\
\hline Nest 2 parameter $\left(\lambda_{2}\right)$ & $\mathrm{n} / \mathrm{a}$ & $\mathrm{n} / \mathrm{a}$ & $\mathrm{n} / \mathrm{a}$ & $\mathrm{n} / \mathrm{a}$ & -2.360 & -2.578 & $\mathrm{n} / \mathrm{a}$ & $\mathrm{n} / \mathrm{a}$ \\
\hline Log-likelihood & & -1391.4 & & -1390.0 & & -1385.5 & & -1390.1 \\
\hline McFadden $\mathrm{R}^{2}$ & & 0.138 & & 0.139 & & 0.142 & & 0.139 \\
\hline
\end{tabular}

Notes: $\mathrm{RS}=$ rideshare, NRS = non-rideshare, TEL = telecommute, IDK = I don't know 
The three employment/commute variables significant in Model 1 are also significant in the MNL model. Those who work less than four days a week are more likely to telecommute than use another option. People whose work requires midday vehicle trips would most likely not know what to do if they could not drive to work alone, implying that a company vehicle is likely not available and having vehicle access is vital to their jobs. The reported travel times variable is the only one that resulted in statistically significant coefficients for all three interactions with the non-referenced alternatives, confirming its importance (Tsao and Lin 1999; Teal 1987; Belz and Lee 2012). Intuitively, those with high travel times are less likely to use a non-rideshare mode and more likely to telecommute or not have other travel options, compared to ridesharing. In addition, the dummy variable for having work schedule flexibility is associated with those who are more likely to use a non-rideshare mode, and most likely to telecommute, than to rideshare.

Three built-environment variables, one self-reported and two measured, were found to be associated with various alternatives in the MNL model. Those who reported not having transit available in their neighborhood are less likely to choose a non-rideshare mode and more likely to not know what do, compared to being in a rideshare. Residents living in Census tracts with high residential densities (defined as $\geq 420$ households/kilometers ${ }^{2}$ ) and workers who have greater number of retail businesses within 1-kilometer radius of their work location are more likely to choose non-rideshare than to coordinate rides; this is intuitive since transit service and walk/bike facilities tend to be more commonly available in areas with dense populations and an abundance of commercial activities.

Unlike Model 1, none of the attitudinal variables were found to be statistically significant in the MNL model. As such, none were included.

\subsection{Model 3: Using a rideshare program}

The last set of results is presented in Table 7 for the binomial logistic regression model of those who would use a rideshare program. It includes fewer explanatory variables than the previous models and has a Nagelkerke pseudo r-square of 0.086. Annual household income, specified as $\$ 10,000$ per year per household size, is one of the statistically significant variables. Since 194 respondents did not answer the income question, the sample size for this model was reduced to 1601 .

All four household/demographic variables in Model 3 had negative associations with using a registered rideshare program with someone the respondents did not personally know. Unlike the previous models, females and younger commuters are less likely to use such a program, possibly due to concerns of interacting with strangers. Interestingly, those with an educational level of less than a bachelor degree are unlikely to participate in this type of rideshare program, as are people in households with high annual income per person. This finding appears to be contradictory and is worthy of further consideration.

Only one employment variable is statistically significant in Model 3. Those who work three to five days a week are more likely to use this rideshare program than those who work less than three or more than five days. This could be because of the need for flexibility for those who do not work often or need to commute on the weekend. 
Table 7: Model 3-Binomial logistic regression model of using a rideshare program

\begin{tabular}{|l|r|r|r|}
\hline Variable & Coefficient & Wald Z & $\operatorname{Pr}(>|Z|)$ \\
\hline Intercept & 0.649 & 3.34 & 0.0008 \\
\hline Household/demographic & & & \\
\hline Female & -0.253 & -2.29 & 0.0219 \\
\hline Younger than 45 & -0.552 & -4.88 & $<0.0001$ \\
\hline Associate degree or less & -0.536 & -4.84 & $<0.0001$ \\
\hline Annual household income (\$10,000/person) & -0.008 & -2.42 & 0.0153 \\
\hline Employment/commute & & & \\
\hline Work 3 to 5 days/week & 0.352 & 2.9 & 0.0037 \\
\hline Built environment & & & \\
\hline Count of retail business within 10-km radius of home & 0.564 & 5.14 & $<0.0001$ \\
\hline Work near CBD ( $\leq 2.25$ km) & -0.303 & -3.25 & 0.0011 \\
\hline Attitudes & & & \\
\hline Not concerned about need to come and go & 0.293 & 2.43 & 0.015 \\
\hline Number of observations & 1,601 & & \\
\hline Yes to registered rideshare program & 988 & & \\
\hline No to registered rideshare program & 613 & & \\
\hline Nagelkerke R & 0.086 & & \\
\hline
\end{tabular}

Two built-environment variables, one measured from the home location and the other measured from the work location, are of note in this model. Residents who have a high count of retail businesses within a 10-kilometer radius of their home are less likely to participate in a registered rideshare program but those who work near a CBD (defined as $\leq 2.25$ kilometers) are more likely to participate. Interestingly, this work near CBD dummy has the same distance threshold as the list near CBD dummy found to be significant in Model 1. It is possible that at this distance, residents are in dense enough neighborhoods to find rideshare opportunities but not dense enough for an abundance of other non-driving options.

The last significant variable in Model 3 is an attitudinal dummy for those who are not concerned about the need to come and go when desired. Not surprisingly, those with that attitude are more likely to use a registered rideshare program than those who have travel restriction concerns.

\section{Conclusions}

The summary Table 8 allows some generalization related to current rideshare commuters versus potential rideshare commuters and those willing to use a rideshare program. It also shows the usefulness of different variable classes for this topic.

First, the models together suggest that workers who would self-organize rideshares with a household member or someone they know are not the same as those who would participate in a rideshare program with others they do not know. Gender and age form an interesting comparison. While younger individuals and females are more likely to rideshare, they are not generally willing to participate in rideshare programs that would match them with strangers. 
Table 8: Summary of findings

\begin{tabular}{|c|c|c|c|}
\hline Variable & Model 1 & Model 2 & Model 3 \\
\hline \multicolumn{4}{|l|}{ Household/demographic } \\
\hline Female & + & + & - \\
\hline Younger than 55 & + & + & $\mathrm{n} / \mathrm{a}$ \\
\hline Younger than 45 & $\mathrm{n} / \mathrm{a}$ & $\mathrm{n} / \mathrm{a}$ & - \\
\hline Male and older than 55 (derived from interaction) & - & $\mathrm{n} / \mathrm{a}$ & $\mathrm{n} / \mathrm{a}$ \\
\hline No educational degree & + & $\mathrm{n} / \mathrm{a}$ & $\mathrm{n} / \mathrm{a}$ \\
\hline Associate degree or less & $\mathrm{n} / \mathrm{a}$ & $\mathrm{n} / \mathrm{a}$ & - \\
\hline Multi-person household & + & + & $\mathrm{n} / \mathrm{a}$ \\
\hline More drivers than vehicles in household & + & $\mathrm{n} / \mathrm{a}$ & $\mathrm{n} / \mathrm{a}$ \\
\hline Annual household income ( $\$ 10,000 /$ person $)$ & $\mathrm{n} / \mathrm{a}$ & $\mathrm{n} / \mathrm{a}$ & - \\
\hline \multicolumn{4}{|l|}{ Employment/commute } \\
\hline Work less than 4 days/week & - & $\mathrm{n} / \mathrm{a}$ & $\mathrm{n} / \mathrm{a}$ \\
\hline Work 3 to 5 days/week & $\mathrm{n} / \mathrm{a}$ & $\mathrm{n} / \mathrm{a}$ & + \\
\hline Work requires midday vehicle trips & - & $\mathrm{n} / \mathrm{a}$ & $\mathrm{n} / \mathrm{a}$ \\
\hline Reported travel time to work (minutes) & + & + & $\mathrm{n} / \mathrm{a}$ \\
\hline Have work schedule flexibility & $\mathrm{n} / \mathrm{a}$ & - & $\mathrm{n} / \mathrm{a}$ \\
\hline \multicolumn{4}{|l|}{ Built environment } \\
\hline Home in dense tract $\left(\geq 420 \mathrm{HH} / \mathrm{km}^{2}\right)$ & + & - & $\mathrm{n} / \mathrm{a}$ \\
\hline Home near CBD $(\leq 2.25 \mathrm{~km})$ & + & $\mathrm{n} / \mathrm{a}$ & $\mathrm{n} / \mathrm{a}$ \\
\hline No transit available in neighborhood & $\mathrm{n} / \mathrm{a}$ & + & $\mathrm{n} / \mathrm{a}$ \\
\hline Count of retail business within $10-\mathrm{km}$ radius of home & $\mathrm{n} / \mathrm{a}$ & $\mathrm{n} / \mathrm{a}$ & + \\
\hline Count of retail business within $1 \mathrm{~km}$ of work & $\mathrm{n} / \mathrm{a}$ & - & $\mathrm{n} / \mathrm{a}$ \\
\hline Work area ruralness (RUCA2; 1 through 10) & + & $\mathrm{n} / \mathrm{a}$ & $\mathrm{n} / \mathrm{a}$ \\
\hline Work near CBD $(\leq 2.25 \mathrm{~km})$ & $\mathrm{n} / \mathrm{a}$ & $\mathrm{n} / \mathrm{a}$ & - \\
\hline \multicolumn{4}{|l|}{ Attitudes } \\
\hline Prefer to be driver over passenger & - & $\mathrm{n} / \mathrm{a}$ & $\mathrm{n} / \mathrm{a}$ \\
\hline Not important to live close to work, school, friends & - & $\mathrm{n} / \mathrm{a}$ & $\mathrm{n} / \mathrm{a}$ \\
\hline Important to have private home location & - & $\mathrm{n} / \mathrm{a}$ & $\mathrm{n} / \mathrm{a}$ \\
\hline Not concerned about need to come and go & $\mathrm{n} / \mathrm{a}$ & $\mathrm{n} / \mathrm{a}$ & + \\
\hline
\end{tabular}

Note: $\mathrm{n} / \mathrm{a}=$ not statistically significant

In general, built-environment variables reveal relative differences between urban and rural areas. Residents who live in urban neighborhoods and work in rural locations are more likely to be a current rideshare commuter and more willing to participate in a rideshare program. However, individuals who live and work in urban areas do not generally indicate rideshare as an option if they cannot drive alone (Model 2). One can hypothesize that this is due to urban residents having more options for travel than their rural counterparts. Together, these factors suggest rural workplaces as a potential target audience to increase ridesharing.

In this study, many attitudinal measures about travel and land use were surveyed. Although three of the attitude variables were significant in explaining current ridesharing behavior, the attitude variables were not useful for explaining potential rideshare commuters or willingness to participate in a rideshare program. This suggests that other questions concerning attitudes on environment or energy, such as 
those used in some studies on transit demands, may be more suitable.

Overall the model results indicate that those who can commute by rideshare now and those who may be helped by a formal program to find rideshare opportunities are different individuals in different locales of home and work. This segmentation may form a useful basis for future data collection efforts and ultimately program development including identification of target users.

\section{References}

American Association of State Highway and Transportation Officials. 2013. Commuting in America 2013: National Report on Commuting Patterns and Trends. http://traveltrends.transportation.org/ Pages/default.aspx

Belz, N., and B. H. Y. Lee. 2012. Composition of vehicle occupancy for journey-to-work trips, evidence of ridesharing from the 2009 National Household Travel Survey Vermont Add-on Sample. Forthcoming Transportation Research Record.

Cervero, R. 1996. Mixed land-uses and commuting: Evidence from the American Housing Survey. Transportation Research Part A-Policy and Practice 30(5): 361-377.

Charles, K., and P. Kline. 2004. Relational costs and the production of social capital: Evidence from carpooling. The Economic Journal 116(511): 581-604.

Chatman, D. 2003. How density and mixed uses at the workplace affect personal commercial travel and commute choice. Transportation Research Record 1831: 193-201.

Frank, L., and G. Pivo. 1994. Impacts of mixed use and density on utilization of three modes of travel: Single-occupant vehicle, transit, and walking. Transportation Research Record 1466: 44-52.

Hartgen, D. 1977. Ridesharing Behavior: A Review of Recent Findings_Preliminary Research Report 130. Albany, NY: New York State Department of Transportation.

Hunt, J., and J. McMillan. 2007. Stated-preference examination of attitudes toward carpooling to work in Calgary. Transportation Research Record 1598: 9-17.

Hwang, K., and G. Guiliano. 1990. The Determinants of Ridesharing: Literature Review. Berkeley, CA: The University of California Transportation Center, University of California at Berkeley.

Kaufman, S. 2002. Why people (don't) carpool and change for the better. Second International Conference on Sustainable Campuses, Oct. 2-4, 2002, Melbourne, Australia.

Kockelman, K. 1997. Travel behavior as a function of accessibility, land use mixing and land use balance. Transportation Research Record 1607: 117-125.

Leck, E. 2006. The impact of urban form on travel behavior: A meta-analysis. Berkeley Planning Journal 19: 3758.

McGuckin, N., and N. Srinivasan. 2003. Journey-to-work in the United States and its Major Metropolitan Areas; 1960-2000. Washington, DC: United States Department of Transportation Federal Highway Administration.

Pisarski, A. 2006. Commuting in America III: The Third National Report on Commuting Patterns and Trends. Washington, DC: Transportation Research Board of the National Academies.

Rural-Urban Commuting Area Codes (RUCAs). http://depts.washington.edu/uwruca/.

Shiftan, Y., and Y. Barlach. 2012. Effect of employment site characteristics on commute mode choice. Transportation Research Record 1781: 19-25.

Silvia, J., and D. Niemeier. 2009. Social network and dwelling characteristics that influence ridesharing behavior of seniors. Transportation Research Record 2118: 47-54.

Teal, R. 1987. Carpooling: Who, how, and why? Transportation Research Part A 21(3): 203־-214. 
Tsao, H., and D. Lin. 1999. Spatial and Temporal Factors in Estimating the Potential of Ridesharing for Demand Reduction. Berkeley, CA: California PATH Program, Institute of Transportation Studies, University of California.

Van Lange, P., M. Ban Vugt, R. Meertens, and R. Ruiter. 1998. A social dilemma analysis of commuting preferences: The roles of social value orientation and trust. Journal of Applied Social Psychology 28(9): 796-820. 